\title{
Control Systems for Street Lighting
}

\author{
Peter Janiga ${ }^{1)}$, Lukáš Lipnický ${ }^{2)}$ and Dionýz Gašparovský ${ }^{3)}$ \\ 1) 2) ${ }^{3)}$ Faculty of Electrical Engineering and Information Technology STU, Institute of Power and Applied Electrical \\ Engineering, Bratislava, Slovakia, \\ e-mail: ${ }^{1)}$ peter.janiga@stuba.sk, ${ }^{2)}$ lukas.lipnicky@stuba.sk, ${ }^{3)}$ dionyz.gasparovsky@stuba.sk
}

\begin{abstract}
Public lighting is a specific type of lighting system with various requirements. It is a lighting system which is subject to many influences. Some impacts are changing very rapidly but a lighting system is designed for a specific case. These effects are for example the traffic density or impact of weather. Comprehensive regulation taking into account all the effects does not currently exist but particular systems taking into account the subtasks are occurring. The aim is to show the possibilities and also the technical prerequisites for the realization of such systems.
\end{abstract}

Keywords — public lighting, adaptive control, dimming

\section{INTRODUCTION}

Public lighting is now in all larger towns and in all municipalities in Slovakia. The operation charges represent a significant amount of a budget item. Operator of a public lighting tries to rationalize it and to reduce cost for this reason [2]. In the past the consumption decreased by using more efficient light sources and more efficient optical materials. Currently, the reconstructions are focused on exchange of lamps for more efficient LEDs.

Another potential for consumption reducing and efficiency increasing is the adaptive control of the public lighting. The simplest control system is based on requirement change in late night hours. The control system reduces luminous flux and also reduces lamp power consumption. This system uses the principle of lower requirements in late night when streets are less used and street can be reclassified to a lower class. Reducing of the lamp power consumption will be realized individually in the lamp (dimmable ballast) or centrally in the cabinet (voltage regulator in the control cabinet) [1].

Next step for increasing the efficiency is the adaptive lighting control. In this control the luminous flux and lamp consumption is regulated mainly according the street utilization. This system reduces the lighting level to minimum (typically $10 \%$ ) if no users are using street lighting. Actual consumption of lamps depends on the current lighting profile. The adaptive lighting changes luminous flux often and in a wide spectrum. This often changing is for LED lamps the most suitable. Lamps with discharge light sources are not recommended.

Some new adaptive systems of the public lighting can shortly increase luminous flux over the standard power. This takes place in case of a road accident or when ambulance, police or firemen are passing the road. These increases are for safety of drivers and pedestrian users. These systems require communication between the emergency vehicle and the lighting system. Some systems can detect colour of emergency car flashing without communication. These systems are very sophisticated solutions and they are in the state of studies.

\section{OPERATION PROFILES FOR ADAPTIVE LIGHTING}

The topic of operation profiles is particularly described in the standard EN 13201-5. Typical lighting control profiles include:

- Full control profile: It is used for simple public lighting networks for many years until nowadays. Networks are switched through photocells or timers and so on. A full range profile is used in most old public lighting networks. Such lighting networks should be used after renovation or in a new public lighting only for roads with a constant traffic.

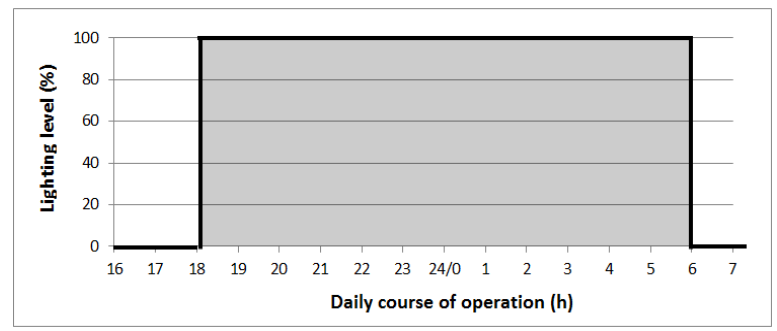

Fig. 1. Example of full control profile.

- Multi-level control profile: It is made of two or more time intervals within the day course, during which lamps have different power consumption and provide different light levels in accordance with the classification of roads in the lighting classes (according to EN 13201-2) for each of the intervals. This profile is suitable for roads with lower traffic density when lower frequency of cars on the road at night is assumed. For dimming control can be used various voltage controllers, phase controllers, dimmable electronic ballasts.

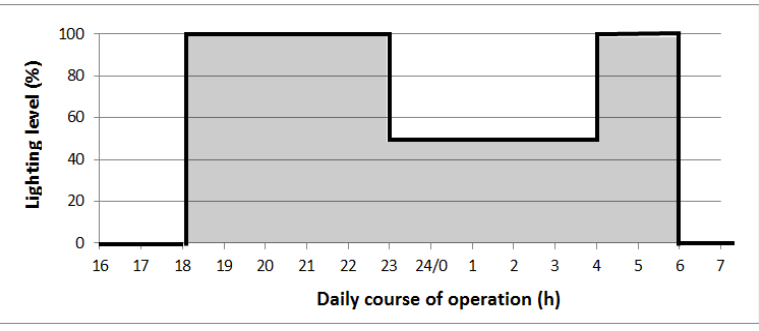

Fig. 2. Example of two level control profile. 
- Night lighting turning off: They sometimes occur in small towns and villages for electric energy saving purposes. The lighting system is fully switched off at the night time. This regime is used in the lighting systems with simple switching elements where technically it is not possible to install a cost effective lighting control system. This profile is not recommended to use due to security reasons. Therefore it is not mentioned in the standard EN 13201-5. However by switching off of the lighting system energy saving is achieved but in this regime purpose of the lighting system for which it was designed is lost i.e. mainly for secure feeling in the town or city. Completely switched off lighting system brings also security risk for car drivers for whom it is very difficult to observe a barrier on the road as pedestrians, animals etc. It is acceptable around astronomic observation places where pollution light prevents observations quality of night sky and so on.

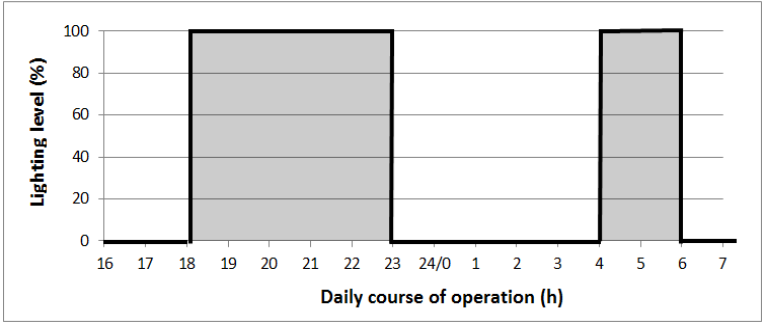

Fig. 3. Example of lighting turning off profile.

- Lighting control using movement sensors of vehicles and persons: If the lighting system is controlled by movement detectors of cars and persons, the full or multilevel profile is switched to lower minimum illuminance levels than usually when traffic is not detected. At night time after sunset for this purpose it is defined a new, third illuminance level of the lighting system which represents a minimum security risk for other people which are living in an area with this controlling system (secure movement of pedestrians in the case when detection system failed, minimum level for habitants of buildings looking from windows). Simultaneously this controlling system should maintain luminaires in standby mode. It is particularly suitable for the LED luminaires which are easily controllable for various illuminance levels. Levels when the traffic is not detected depend on the detection and they are not periodic. For the determination of AECI (Annual Energy Consumption Indicator) it is therefore needed to assume some probability of higher illuminance levels at time of detection for each illuminance level of the lighting system. This controlling system should be used in a residential area.

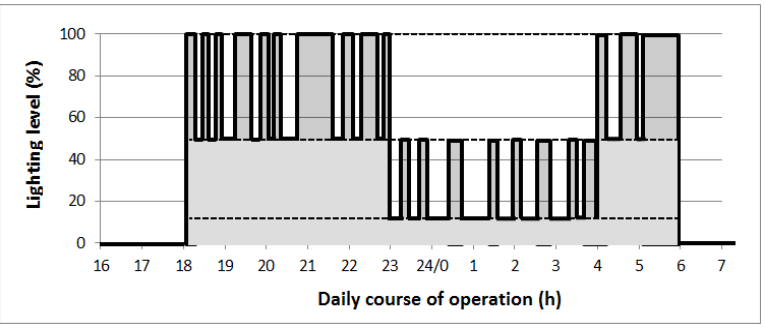

Fig. 4. Example of multi-detection of cars and pedestrians profile.

\section{EFFICIENCY OF ADAPTIVE LIGHTING}

For a full control profile it is usually considered the annual operating time 4000 hours of public lighting (Central Europe). With other operating modes it is usually sufficient to combine an annual operating time of each light level with the appropriate system input and in the case of systems with sensors and the probability of detection. In this way the operation of the lighting ratio calculated the coefficients of operation (cop). Typical values of the coefficient of operation of the lighting control profiles for different states are in Tab. 1, the values in the table were determined under the following conditions:

- Full profile: 4,000 hours at full power P.

- Two-level profile: 2,175 hours at full power $\mathrm{P}$ and 1825 hours at a reduced power $0,7 \mathrm{P}$, the level of lighting reduced to $50 \%$.

- Turn off the light at night: Like the two-level profile, but with zero input during 1825 night hours (loss of service).

- Three-level profile with sensor: 2175 hours of twolevel control between $100 \%$ and $60 \%$ of the system input with a probability of detection of $80 \%$ and a reduced 1825 hours of two-level control between $20 \%$ and $60 \%$ of the system input with a probability detecting $20 \%$.

TABLE I.

TyPiCAL VALUES OF THE COEFFICIENT OF OPERATION

\begin{tabular}{|c|c|}
\hline Operation profile & $\mathrm{c}_{\mathrm{op}}(\%)$ \\
\hline Full profile & 100,0 \\
\hline Two-level profile & 86,3 \\
\hline Three-level profile & 62,8 \\
\hline Turn off the light in the night & 54,4 \\
\hline
\end{tabular}

This assessment is used to calculate the AECI (Annual Energy Consumption Indicator). From this it is to see the potential savings from the different levels of management.

\section{WEATHER CONDITION IMPACT}

For complex controlling of lighting level it is necessary to take in account also weather condition. If the carriageway is continuously overlaid with snow it is possible to notice an increase of luminance on the road and surroundings. This effect can be rated like positive. It is possible to assume, that a decrease of the luminous flux level of luminaries ensures the needed illumination on the road and along with lower power consumption.

For exact definition increase of the luminance values on the road is needed to consider the conditions on the carriageway. That means:

- new or slick snow,

- continuous layer or running out lines,

- uniformity and quantity of snow.

Wet surface is among the most common impact that can occur on the road. Rain has negative impact on the luminance on the road. Rain and wet road increase risk of glare from the oncoming cars, public lighting, surrounding lighting and so on. Main impacts influencing the luminance on the wet carriageway are: 
- water in running out lines,

- water fog from other cars,

$$
\text { - puddle. }
$$

The worst negative impact on a wet carriageway is alternation of bright and dark places. The human eye cannot adapt on the fast changes and then cannot discern details on the road. These effects are difficult to quantify and measure.
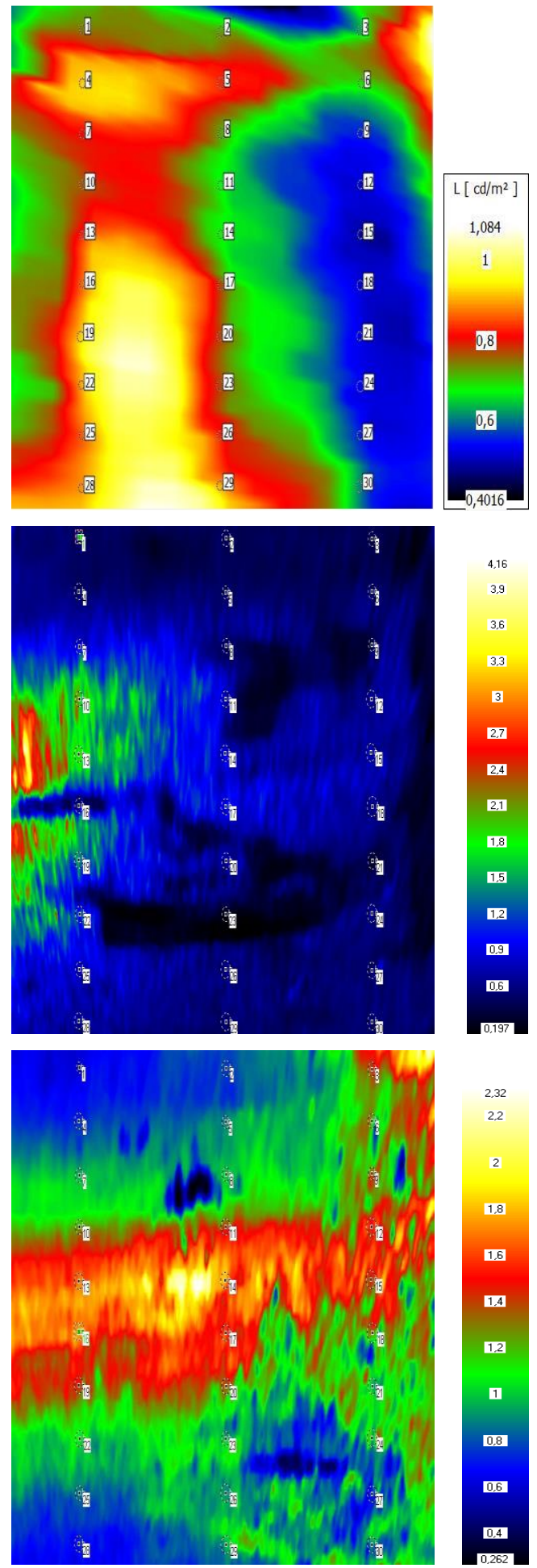

\section{IMPACT OF SURROUNDING OBJECTS}

The surrounding objects affect the illumination level on the roads. This effect is often variable during daytime hours. The increase of the luminous flux from the surrounding buildings and objects is in the evening. This phenomenon may be positive but also negative.

The illumination from the surrounding buildings can be used to illuminate the surrounding roads such as sidewalks. This may cause no uniformity of the illumination. It can be caused by the show-window illumination or illumination of the building facades.

The above-described effects of buildings and objects are positive but the surrounding objects can also increase the risk of glare. It is necessary to increase the background illuminance in this case. Increase of the background illumination is provided by using public lighting.

The most important effects of surrounding buildings are:

- building illumination,

- billboards,

- show-window illumination,

- seasonal decoration illumination,

- floodlighting.

In the surroundings of roads and communications leafy trees and density of leaves change during the year. Transmittance of light through the trees is better during the winter months when the leaves fell. Full treetops seem like an aperture in summer and autumn.

\section{TECHNICAL SOLUTION}

Several studies describe adaptive public lighting networks. The commencement of this technology into practice is slow. A reconstruction with adaptive technologies is a significant investment and technology is not sufficiently adjusted. One of the possible solutions is described in Fig. 2. On the lamppost motion sensors are placed close to the lamps. These detected motions and signals are processed with algorithms. A control unit increases or decreases the lighting level in dependence on the street using. All lighting levels have to satisfy standard requirements for the illuminance and luminance. Algorithms for control have to take in account:

- View of a user in the direction of walking or driving.

- View of a user in the back.

- View of a user to surroundings, sidewalks and other lanes of the street and road.

- View in all directions from junctions.

The algorithm and processor have to switch the lighting level during the using time. Switching to a lower level has to have delay for standing people or for people leaving the street.

Advanced technologies can separately manage the lighting in different parts of the street. For example, the lighting on the road may not be $100 \%$ for the case of a pedestrian on the sidewalk and when no vehicle is on the road. These algorithms require control of the individual LED chips.

Fig. 5. Comparison of one driving lane for dry, wet and snowy surface. 


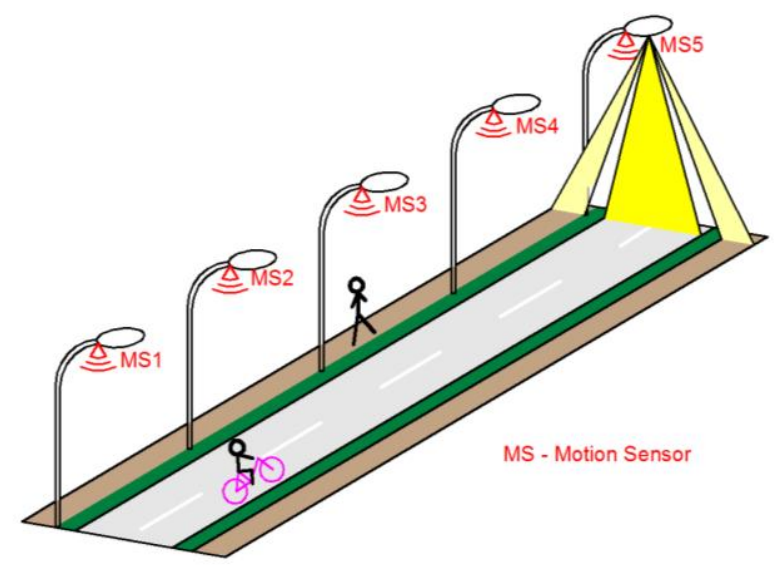

Fig. 6. Adaptive street lighting.

The laser sensor use can evaluate the size of a moving object, its speed, direction and distance from the sensor. All described technical solutions require visibility from sensors to street and its surrounding. Usually data collection from sensors and control of the luminous flux provided by the control unit are located in the supply cabinet. A solution for a spacious area is necessary to ensure communication between the controller, lamps and sensors and also harmonize their assistance.

At present, the biggest problem is appropriate selection of the motion sensors and sensitivity settings. Typical motion detectors are:

- Passive infrared detector.

- Infrared fence.

- Microwave sensors.

- Laser detector.

These sensors are nowadays on a high quality level but usually are developed for the detection of people indoors or in conjunction with other sensors to protect the exterior prior to an unauthorized entry. Adapting to detect the movement of people on roads would almost always require some adjustments to eliminate false impulses e.g.:

- Weather (rain, snow, fog).

- The effects of wind and greenery and trees movement.

- Impact of animal movements.

Other complications may represent dirt on the sensor. The use of sensitive detectors requires regular maintenance. For less sensitive sensors it will be again required to use more of them. A major problem of the adaptive lighting control is shielding by various structures and greenery. Often, such communication closing is caused by dense greenery, billboards, etc., which may prevent the motion detector to respond properly to the proximity of people.

\section{DESIGN OF ADAPTIVE LIGHTING}

At present design of an adaptive lighting is not just a simple engineering work but also experiments are required. It is the result of a small amount of information and experience.

Slovakia has implemented two pilot projects. The first one eliminates a lot of troubles choosing communication where there is green and the street is narrow with a single path. PIR sensors placed in the lanterns are used. The second pilot project aims to solve more technical problems and analyses of the impacts. As part of this project authors of this paper are also involved. Current assessments carry out technical solutions and measuring of the light-producing and electrical parameters. Light parameters provide information on changes in the management of lighting. Electrical parameters give information on energy saving and impacts on the supply.

In Austria a currently operated way is with a precision adaptive lighting. It is set up for movement and some parts are also setup for adapting weather conditions.

As the proposed adaptive lighting in most cases requires an individual approach, the optimal approach would be to use existing programmes when designing a solution.

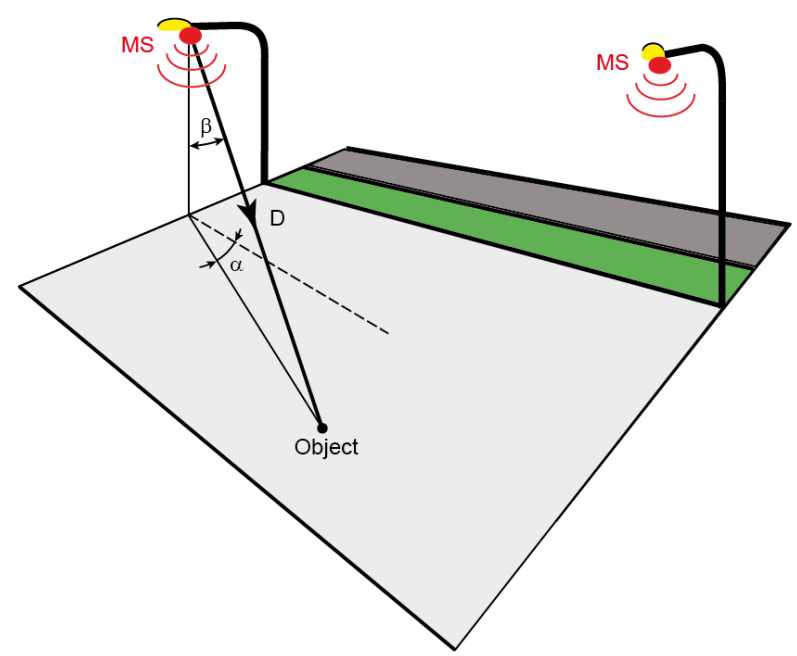

Fig. 7. Motion sensor settings.

Modelling programmes for the light calculation encompasses modelling obstacles. When choosing and setting up sensors, it is possible to use these programmes. In a simplified form it can be assumed that if the sensor is closer to the lamp the sensor sees the same subjects which the lamp illuminates. In Fig. 7 and Eq. (1), the selection and adjustment of the sensor are so that the distance of a moving object is in or below the resolution of the sensor.

$$
\bar{D}=(\alpha, \beta, D)
$$

where: $\alpha-$ horizontal angle, $\beta-$ vertical angle, $D$ - distance from sensor.

\section{SELECTING STREETS FOR ADAPTIVE LIGHTING}

It is one of the most important steps in the design of the adaptive public lighting. A rational solution is appropriate if it seeks at all costs solutions for complex and heavily used communication.

In Fig. 8 an example of a suitable communication is depicted. The communication is located in a residential area, which represents a significant saving potential. The lighting system is before reconstruction. When placing the sensor near the pole-mounted luminaires problems arise with obstacles. Distance poles and breadth of communication is not great, so just standard sensors will do. 


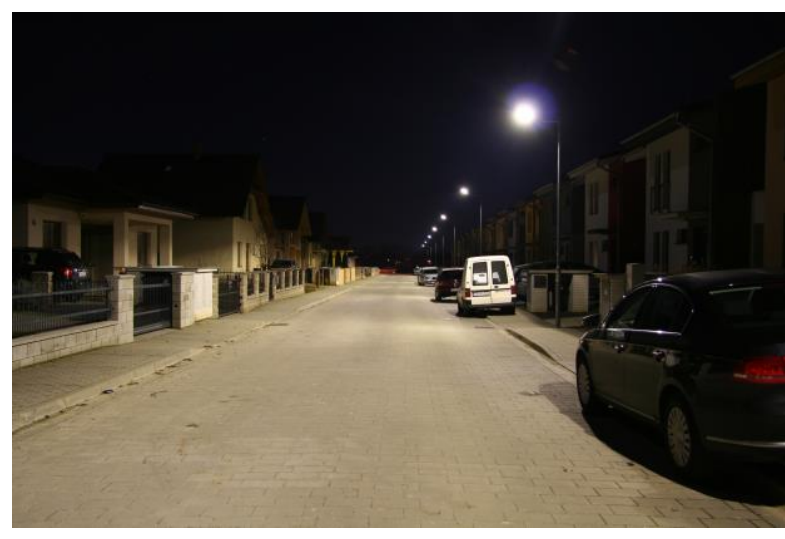

Fig. 7. Apposite example of street situation.

The communication unsuitable for the adaptive lighting features is in central parts of towns and routes with frequent movement of people and vehicles because of a long payback. It is also not advisable to install an adaptive lighting of a park and winding communications. In these cases, it is needed to install more sensors for higher probability of false detected or undetected movement.

\section{CONCLUSION}

Public lighting is currently designed and operated to meet the standard requirements. But often the case that the communication is illuminated when there are no walkers or drivers. Some communications are illuminated by more than half of the time without use, which offers potential savings. Since the adaptive lighting is a relatively new technology, it is necessary to approach responsibly to tackling order to avoid rapid and inconsistent solutions. The positive is that the first pilot projects enables designers to provide practical information and operator experience to know what to expect from the new technology. Because of these innovative technology municipalities raises concerns about the reliability of the solution.

\section{ACKNOWLEDGMENT}

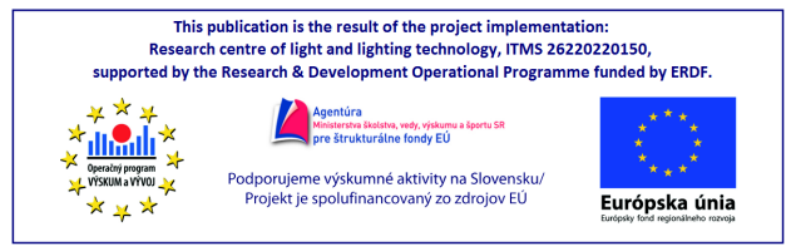

\section{REFERENCES}

[1] A. Beláň, B. Cintula, Ž. Eleschová. "Power quality measurement with focusing on voltage sags evaluation" In Power Engineering 2016. Energy - Ecology - Economy 2016: 13th International Scientific Conference EEE 2016. Tatranské Matliare, Slovakia, May 31- June 2, 2016. Bratislava: Slovak University of Technology in Bratislava, 2016, s.CD-ROM, s. ISBN 978-80-89402-85-4.

[2] F. Janíček, A. Cerman, J. Kubica. "Are current myths in energy sector real?". In Power Engineering 2012. Energy - Ecology Economy 2012 [elektronický zdroj]: 11th International Scientific Conference EEE 2012. Tatranské Matliare, Slovakia, May 15-17, 2012. Bratislava: Slovak University of Technology in Bratislava, 2012, s.CD-ROM, [5] s. ISBN 978-80-89402-49-6.

[3] EN 13201-5 Road Lighting - Performance Requirements

[4] Schréder, Smart Control for Efficient Lighting

[5] CIE 115: Lighting of Roads for Motor and Pedestrian Traffic

[6] Skoda, J, Baxant, P. The reduction in electricity consumption through proper lighting, In proc. EPE - Electric Power Engineering 2009. Brno University of Technology: Brno

[7] Sokansky, K., Novak, T.: Energy savings in public lighting, Przeglad Elektrotechniczny, 84(8), pp. 72- 74, 2008 